\title{
SOBRE PROJECIONISTAS, IMAGENS E EDUCAÇÃO: MOVIMENTOS CARTOGRÁFICOS DO PENSAMENTO EM UM JOGO DE DADOS EDUCACIONAL
}

\author{
Ingrid Rodrigues Gonçalves ${ }^{1}$
}

\section{Prévias}

Para conhecer dos vaga-lumes, é preciso observá-los no presente de sua sobrevivência: é preciso vê-los dançar vivos no meio da noite, ainda que essa noite seja varrida por alguns projetores ferozes (DIDI-HUBERMAN, 2011, p. 52)

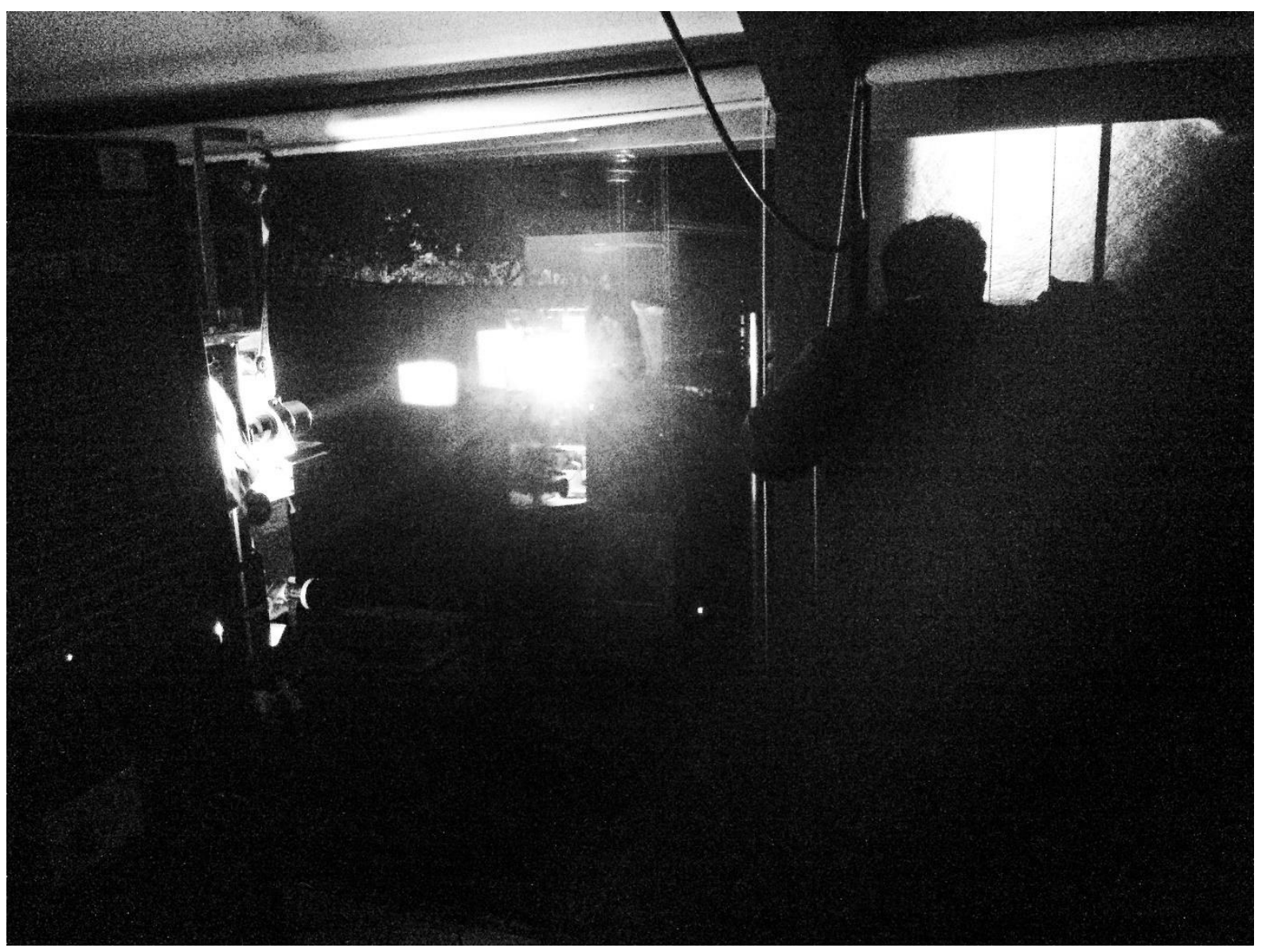

IMAGEM 1 - Mergulho na imagem-água - Fonte: nosso acervo, 2016

Habitar uma sala de cinema não como um espectador, mas como quem se mistura aos corpos fílmicos, aos suportes que abrigam as emulsões, aos pixels espraiando-se para além das telas.

O trabalho de operador cinematográfico (ou projecionista), envolve a preparação prévia e o manuseio dos materiais fílmicos, em diferentes suportes (películas ou arquivos digitais), para exibição ao vivo na sala de cinema. Ademais, seu ofício "está no coração da vida de uma cinemateca" (AUGER, 2004), pois, de seus esforços, dependem "a integridade física dos

\footnotetext{
${ }^{1}$ Mestranda em Educação - Faculdade de Educação da Universidade de São Paulo - USP. Professora do curso de Serviços Públicos - ETEC Cepam Gestão Pública. E-mail: ingrid.goncalves@usp.br.
} 
materiais (frequentemente raros ou únicos)" e, "uma projeção de qualidade [...] obediente aos diferentes padrões (de bitola, velocidade, formato, tipo de som etc.)"”. Nessa toada, as imagens são ao mesmo tempo o material e o resultado de seus lavores em todo o processo de vida dos filmes na sala de cinema, desde quando os recebe enquanto imagem-suporte, passando pelo espetáculo disparado na tela via imagem-projetada, até a desmontagem dos materiais e o zelo fulcral com o maquinário que abrigará o traslado de tais corpos fílmicos.

Dessarte, quando a preservação lidera a lista de objetivos ao invés do lucro das bilheterias do circuito comercial, a responsabilidade aumenta, assim como a gama de conhecimentos necessários e a disposição para constante atualização e pesquisa desse profissional, a quem "cabe resguardar os agenciamentos entre os que 'dançam sem sair do lugar' e as imagens-projetadas", de modo que, "num contexto de projeções em filme fotoquímico", um projecionista "precisa dispor de diversos saberes para manejar uma cabine de projeção" (GONÇALVES, 2016, p. 841).

A implantação do cinema digital alterou consideravelmente os modos de exibição. Segundo dados divulgados pela Agência Nacional do Cinema (Ancine), em 2014 cerca de 40\% das salas brasileiras estavam digitalizadas; no final de 2015 o número já chegava a $80 \%$. No ano seguinte, "de acordo com levantamento realizado junto aos exibidores em dezembro, o parque exibidor brasileiro chegou ao final de 2016 com 3.148 salas digitalizadas, ou 99,6\%" (OCA/ANCINE, 2016, p. 25). O processo de digitalização produz, dentre outras coisas: alterações nas composições relacionais de expansão do acesso e difusão cinematográfica no território nacional; inovações nos encaminhamentos logísticos; diminuição dos custos de produção das cópias; debates acerca dos novos modelos de negócio; movimentações no mercado interno; etc. Processo esse, deveras comemorado por diversos atores do setor. Aos operadores cinematográficos, efeitos diversos.

Com a transição do suporte padrão da película $35 \mathrm{~mm}$ para arquivos digitais, além dos saberes e conhecimentos relativos à projeção analógica, os projecionistas da chamada "velha guarda", especializados nas minúcias e nuances da película, foram tomados de assalto por linhas disruptivas de um aparato tecnológico completamente novo: projetores e players arrastaram aos porões praticamente todo o maquinário de projeção em película, dragando ao descarte, a miríade de conhecimentos outrora basilar a um operador.

Entre 2009 e $2016^{3}$, realizamos entrevistas com projecionistas imersos nesse contexto. Nossa submersão mais profunda ocorreu entre 2009 e 2013, período no qual trabalhamos nas salas de cinema da Cinemateca Brasileira, em São Paulo. Uma das peculiaridades dessa profissão no Brasil, reside no fato de inexistirem cursos profissionalizantes: a transmissão dos modos de fazer ocorre de um para o outro. Daí o baralhar produzido pelos corpos-pixel cinematográficos: uma vez que a projeção padrão passou a ser realizada com projetores digitais, muitos profissionais perderam seus empregos, descompassados na operação das novas máquinas e, envoltos numa espécie de delay, pois seu movimento de partilha de saberes não acompanhou o ritmo das novas demandas.

Entre nós e os operadores, o manejo de máquinas era comum pelo entrecruzamento de saberes, pois eles tinham domínio técnico das projeções, e nós da área técnica de áudio. Daí as

\footnotetext{
${ }^{2}$ Comentário que precede a tradução de AUGER (2004), disponibilizada no blog Preservação Audiovisual, de Rafael de Luna Freire, disponível em: 〈http://preservacaoaudiovisual.blogspot.com.br/2009/03/projecionista-deuma-cinemateca.html >.

${ }^{3} \mathrm{O}$ espaço que este texto busca habitar, diz respeito a desdobramentos de um processo de pesquisa vinculado ao Trabalho de Conclusão de Curso da graduação; à participação no Miragem - Grupo de Pesquisa em Culturas Visuais e Experimentações Geográficas; e, às vivências na Cinemateca Brasileira entre 2009 e 2013 , especificamente, no que diz respeito à convivência com os operadores cinematográficos.
} 
trocas, pois eles sabiam manejar sessões de filmes, mas titubeavam no controle dos microfones e das gravações de áudio.

Nesse texto, pensamos com alguns desses entrelaçamentos de nossas relações com os projecionistas. Para isso, trabalharemos com a ideia de ondas de destruição do crítico francês Raymond Borde (1984), mirando como mudanças nos modos de fazer e pensar o cinema afetaram historicamente a etapa de descarte dos materiais fílmicos. A seguir, trataremos do movimento de hódos-metá cartográfico, tensor constante do caminhar da pesquisa no que diz respeito ao acompanhamento dos processos, às transversalizações, ao funcionamento da atenção, às vivências de cada entrevista, às trocas, e, às relações de uma força com outra, produzindo movimentos no pensamento e jogos educacionais na afirmação de "sua própria diferença", regozijando-se "com essa diferença" (DELEUZE, 1976, p. 9). Diálogos em delay (AQUINO, 2016), os quais tantas vezes não ruidavam palavras, mas agenciavam-se a manejos outros, imbricados em gestos, imagens e sons: referenciais projetados numa mixórdia organizada de tempos e intentos. Vicejos vitais, quiçá.

\section{Ondas de destruição}

A história do cinema é (ou deveria ser) inicialmente a desses momentos em que ver e poder se entrelaçam em um balé de catástrofe (COMOLLI, 2008, p. 16)

A digitalização das salas de cinema brasileiras está atrelada às movimentações mundiais no que se refere à adoção do digital como suporte predominante tanto para a captação quanto para a exibição, e também conecta-se a um processo particular, construído processualmente, de acordo com o caminhar político da cadeia audiovisual nacional ao longo dos anos. O ranço que existia entre os profissionais da sétima arte e aqueles ligados à cadeia TV-Publicidade, desdobrou-se em parcerias no período denominado de Cinema da Retomada. Ideais políticos e embates técnicos e estéticos, deram lugar à inserção dos profissionais em ambos os territórios. Discussões visando uma política nacional do audiovisual mais sólida, desembocaram, na "revisão do conceito de audiovisual brasileiro, incorporando a informática", bem como no apoio à distribuição e construção de novas salas. (MARSON; MELEIRO, 2012, p. 153, grifo nosso).

Os fazeres audiovisuais dizem respeito tanto a produções caseiras, experimentais e/ou amadoras, as quais não têm no lucro o foco de seus esforços, quanto às práticas cinematográficas que conjuminam arte e indústria, como duas forças capazes de produzir múltiplas combinações. Além de estética e poética, também se trata de um negócio, que movimenta mecanismos técnicos, estéticos, comerciais, industriais e institucionais numa ampla estrutura produtiva. Os efeitos desses modelos de negócio afetam diretamente os modos de fazer e pensar o cinema, de modo que a mudança do suporte padrão cinematográfico das películas fílmicas para os formatos digitais alterou significativamente toda a cadeia cinematográfica, desde a captação até a preservação dos materiais fílmicos.

Intentando mirar as transformações tecnológicas na história do cinema desde o olhar da preservação, Borde (1984) delineia historicamente três momentos estratégicos nos quais movimentos disruptivos afetaram massivamente a etapa de descarte de materiais fílmicos. Para o crítico francês, um filme é tanto uma mercadoria quanto um bem cultural, portanto, como mercadoria, está sujeito ao desinteresse do público e dos mercados, assim como, às substituições de paradigmas tecnológicos e estéticos. No artigo "Avatares de un arte vulnerable”, Raymond Borde trata das ondas de destruição (conceito importante para 
pensarmos as movências estruturais do cinema na contemporaneidade), as quais ele descreve terem ocorrido três vezes ao longo da história do cinema.

A primeira, quando há um desinteresse pelo chamado cinema primitivo em meados de 1920, em prol de um cinema mais elaborado. Os materiais fílmicos considerados como antiquados, passam a ser descartados pelos distribuidores, de modo que, boa parte do patrimônio fílmico desaparece. Ele cita como exemplo, que o "Instituto Norte-Americano de Cinema avalia em $85 \%$ o percentual de obras desaparecidas do patrimônio nacional entre 1895 e 1918" (BORDE, 1984, p. 4, tradução nossa ${ }^{4}$ ).

A segunda, ocorre em meados de 1930, na passagem do cinema mudo ao sonoro, com uma alteração técnica significativa pois o tamanho da película passa a ser padronizado com $35 \mathrm{~mm}$ de largura, e, a imagem, a localizar-se de maneira mais estreita na fita para abrigar a pista de som. Nesse rumo, as ondas sonoras estrondeiam a indústria cinematográfica: novos equipamentos de projeção, captação, bem como uma nova geração de atores e a inserção de músicas mudam novamente o soprar dos ventos, demovendo os interesses pelos materiais fílmicos do cinema mudo, os quais passam a ser considerados desinteressantes e têm seu valor comercial rebaixado. A taxa de filmes silenciosos perdidos "atinge $80 \%$ na Itália, $75 \%$ nos Estados Unidos e $70 \%$ na França (Borde, 1984, p. 4, tradução nossa ${ }^{5}$ ). Como galardão por tal ceifa, cinematecas passaram a ser criadas, diante da necessidade de preservação de um patrimônio nacional.

A terceira onda de destruição ocorre na década de 1950, quando o suporte fílmico é substituído do nitrato para o acetato, tendo em vista a elevada inflamabilidade do primeiro, apesar ser mais durável que o segundo. Quantitativamente, as perdas giraram em torno de $50 \%$. Qualitativamente, muito da linguagem, corporificada com as nuances narrativas que o cinema silencioso dava às colorações das películas, se perdeu, tendo em vista a urgência das copiagens em massa, como nos explicou a pesquisadora de acervos audiovisuais Maria Fernanda Curado Coelho.

Na Europa especificamente, o ambiente era de pavor por tudo que é explosivo, porque eles estão saindo da $2^{\text {a }}$ guerra [...] os arquivos (instituições) que começaram a nascer de uma maneira muito forte na passagem do cinema mudo para o sonoro, se veem na segunda metade da década de 50, optando por fazer copiagens em massa, para transferir os filmes de nitrato para acetato. Nesse momento, a política era: copia e queima! Mas, ao optar por uma migração em massa, não há condições de fazer isso com detalhes. Não há tempo de particularizar cada objeto para conseguir fazer uma copiagem preciosa, ou seja, é preciso reduzir o nível de detalhe, para ter massa. Hoje sabemos que aconteceram grandes perdas relacionadas ao cinema silencioso, por exemplo, relacionadas ao tingimento e às viragens, as cores que eram agregadas ao filme preto e branco numa época do filme silencioso, e que eram um elemento narrativo fundamental, tão importante quanto qualquer outro. Elas davam a ambientação da paixão, da dor, da leveza... tinha um cuidado... catálogos com cores definidas, como o vermelho forte, vermelho suave, rosa e a indicação de qual era a situação dramática em que deviam ser usadas. Era uma linguagem mesmo, que era utilizada. Quando os arquivos optam por fazer uma copiagem em massa, eles não têm tempo de fazer esse tipo de detalhamento. Então, as cores do cinema silencioso que vemos hoje são descoradas... E os originais foram queimados! Contraditoriamente, por

\footnotetext{
4 "El Instituto Norteamericano de Cine evalúa en un $85 \%$ el porcentaje de obras desaparecidas del patrimonio nacional entre 1895 y 1918 " (BORDE, 1984, p. 4).

5 “Alcanza un 80\% en Italia, un 75\% en Estados Unidos y un 70\% en Francia” (BORDE, 1984, p. 4).
} 
falta de recursos, os países mais pobres não fizeram essas transferências em massa, então muitos nitratos sobreviveram nos países mais pobres porque eles não tiveram condições de passar para o acetato, e, portanto, não queimaram o seu nitrato. Então, essa foi a terceira onda, há uma grande queima em massa, uma grande perda de obras! (Trecho de entrevista com Maria Fernanda Curado Coelho ${ }^{6}$ )

Outros fatores de destruição apontados por Raymond Borde ao longo dos anos relacionam-se à degradação química dos materiais fílmicos. Adentrando nossos dias, na esteira do arquivista espanhol Alfonso del Amo García, Costa (2013) diz estarmos vivenciando a quarta onda de destruição, na qual o suporte padrão passa da película aos formatos digitais.

A quarta onda de destruição teve início em 1992, com o uso de sistemas digitais nas pós-produções dos filmes. A chegada do "cinema digital" é uma questão contemporânea que impulsiona uma mudança de paradigmas na teoria e na prática da preservação, como atestam: a fragmentação da produção e da exibição dos filmes em multiplataformas (sala de cinema, televisão, internet, celular etc.) e a apropriação da linguagem cinematográfica pelo senso comum, aprendendo-a no cotidiano, sem a necessidade de especialização para se obter resultados satisfatórios (COSTA, 2013, p. 26).

Ora, se hodiernamente o interesse do público e dos mercados pende para relações mediadas por múltiplas telas, e, ademais, com a produção e o consumo de imagens esparramando-se pelos mais variados dispositivos, seria de se esperar esse irremissível movimento de gradativa diminuição dos fazeres cinematográficos coligados às películas, ao passo que os formatos digitais espraiaram-se, agenciando-se a nossos modos de vida. Pensando novamente com Fernanda Coelho: "Temos todos os elementos. É uma mudança tecnológica profunda, o mercado está buscando a imagem digital e desprezando a imagem fotoquímica, com uma tecnologia que é mais frágil do que a anterior" 7 .

Para os distribuidores, há chamarizes atinentes à diminuição do custo das cópias (de até $90 \%$ ); assim como às facilidades logísticas, já que um longa-metragem em película costuma ser dividido em várias partes e ter volume e peso bem elevados, se comparados aos pequenos Hard Disks que abrigam os arquivos digitais ${ }^{8}$.

Pensando com a perspectiva da preservação, vislumbra-se um problema de gravidade considerável, pois não há garantias de vida longa ao digital no longo prazo (AMPAS, 2009; 2015), tendo em vista que notórias rompeduras nos modos de fazer e pensar o cinema avessaram movimentos outrora postos: ao invés de objetos fílmicos, agora são os corpos-pixel que solicitam morada aos acervos e, outrossim, aos nossos HDs domésticos, cada vez mais atochados de imagens (GONÇALVES, 2016).

Nessa dança dos corpos fílmicos, na qual "ver e poder se entrelaçam em um balé de catástrofe" (COMOLLI, 2008, p. 16), percebemos quão rara é a participação dos operadores

\footnotetext{
${ }^{6}$ Excerto obtido por meio de uma entrevista gravada em áudio no dia 11/11/2015, cujo entrevistado assinou termo de concessão.

${ }^{7}$ Excerto obtido por meio de uma entrevista gravada em áudio no dia 11/11/2015, cujo entrevistado assinou termo de concessão.

8 "Para lançar um filme em película, o distribuidor gasta de $\mathrm{R} \$ 3$ mil a $\mathrm{R} \$ 4$ mil por cópia. Com a digitalização, ele passa a gastar $\mathrm{R} \$ 400$ para transferir o filme para um $\mathrm{HD}$, que pode ser utilizado em várias salas e enviado por correio. E, num futuro breve, nem haverá esse custo, porque os filmes poderão ser transmitidos por satélite" (MIRANDA, 2014). Disponível em: 〈http://oglobo.globo.com/cultura/processo-de-modernizacao-dos-cinemasbrasileiros-esta-atrasado-11216067>. Acesso em: 07 out. 2015.
} 
cinematográficos nas discussões acerca da digitalização das salas de cinema. Ademais, sua organização histórica buscou crivar outras discussões políticas, pautadas por exigências a direitos trabalhistas, inserção de legislação específica para a profissão nas leis vigentes, condições de trabalho mais adequadas e salubres (como por exemplo a alta exposição à ruidagem das cabines de projeção e às lâmpadas xênon dos projetores de película, fatores que se constituíam em motivos de discussão, por serem prejudiciais à saúde desses profissionais), dentre outras questões. Ouvimos de empresários e projecionistas, relatos de demissões em massa em todo o Brasil, bem como prenúncios da possibilidade do fim da profissão de projecionista como esta se configurou ao longo dos anos, enquanto o suporte padrão para exibições era a película.

Desse modo, por terem concentrado seus esforços de diálogo em outras frentes, os operadores cinematográficos raramente participam de discussões acerca da transição tecnológica em questão. Conforme o processo de digitalização das salas de cinemas acontecia, diversos operadores cinematográficos não conseguiram se adaptar aos novos procedimentos de trabalho em tempo de permanecerem em seus empregos. De acordo com Jesus Barbosa, presidente do Sindicato dos Operadores Cinematográficos do Estado de São Paulo (Socesp), em algumas empresas exibidoras a redução do quadro funcional chegou a atingir $80 \%$ dos operadores cinematográficos ${ }^{9}$. Noutros fluxos, alguns projecionistas nem mesmo consideram a projeção digital como sendo "cinema" e questionam com frequência a validade dos novos procedimentos de trabalho vigentes nas cabines digitalizadas.

Esse estranhamento diz respeito a uma outra lógica de trabalho, um modo diferente de experienciar a projeção, consideravelmente descolado dos processos envoltos em uma projeção digital. Por se tratar de um arquivo de computador, comandado por softwares específicos e acionado através de uma interface muito semelhante às playlists utilizadas em computadores domésticos, os novos formatos de projeção digital têm alvoroçado muitos operadores cinematográficos, pois as novidades embutem em telas computadorizadas, diversas tarefas diárias realizadas pelos projecionistas em um contexto de projeção com películas. A multiplicidade de conhecimentos exigidos anteriormente de um operador cinematográfico (como noções de mecânica, ótica, preservação, fotografia, eletricidade, dentre outros), saem da ordem do dia e são substituídos por outras interações entre o operador, seu espaço de trabalho, a imagem-suporte e a imagemprojetada $^{10}$.

Para lidar com essas diversas nuances e percepções da pesquisa, enfocamos nossos esforços no acompanhamento dos processos, repensando continuamente as metas da pesquisa e (re)inventando o caminhar, de modo a possibilitar movimentações transversais do pensamento, como nos ensinam algumas das pistas do movimento cartográfico.

\section{Do movimento cartográfico}

O processo relacional da realização de entrevistas desta pesquisa, dialogou com a ideia de um hódos-metá: pistas cartográficas orientando "o percurso da pesquisa sempre considerando os efeitos do processo do pesquisar sobre o objeto da pesquisa, o pesquisador e seus resultados" (PASSOS; BARROS, 2009, p. 17). Atentemos ao cuidado com a palavra "método", a qual deriva dos radicais gregos: metá (o objetivo, o fim) e hódos (o caminho). Trabalhamos pois, com uma inversão de metá e hódos (PASSOS, 2014, 12'40”), compondo com um outro tipo de rigor, no primado da construção das metas conforme o caminhar da pesquisa: "não se busca estabelecer um caminho linear para atingir um fim. A cartografia é

\footnotetext{
${ }^{9}$ Dados recebidos por e-mail em 15/01/2016.

${ }^{10}$ Em Gonçalves (2013), pensamos as relações entre operador cinematográfico, cabine de projeção, imagemsuporte e imagem-projetada.
} 
sempre um método ad hoc" (KASTRUP, 2009, p. 33). Compreendendo que os caminhos não estão dados, são ad hoc, o cartógrafo "sabe que deve inventá-los em função daquilo que pede o contexto em que se encontra” (ROLNIK, 2014, p. 65-66).

Um exemplo é o trabalho Caminhando, de Lygia Clark (1963), o qual prima pelo ato de criação participativo, pois a obra consiste no recorte de uma "fita de moebius", com as duas pontas coladas ${ }^{11}$. "A auto decretada não-artista deu o objeto da arte na mão de seu interlocutor [...] e estabeleceu que a 'arte é o seu ato"" ${ }^{12}$. Dos diários de Lygia, alguns comentários sobre essa 'não-obra':

'Caminhando' é o nome que dei à minha última proposição. A partir daí, atribuo uma importância absoluta ao ato imanente realizado pelo participante. $\mathrm{O}$ 'Caminhando' tem todas as possibilidades ligadas à ação em si: ele permite a escolha, o imprevisível, a transformação de uma virtualidade em um empreendimento concreto.

A obra é o seu ato. À medida em que se corta a fita, ela se afina e se desdobra em entrelaçamentos. No fim, o caminho é tão estreito que não pode mais ser aberto. É o fim do atalho.

Inicialmente, o 'Caminhando' é apenas uma potencialidade. Vocês e ele formarão uma realidade única, total, existencial. Nenhuma separação entre sujeito-objeto. É um corpo-a-corpo, uma fusão. As diversas respostas surgirão de sua escolha. ${ }^{13}$

Uma ideia de método como percurso, no qual a definição das metas ocorre no próprio trajeto, na imanência do encontro com os materiais. Trajetórias experienciadas no recortar da fita (re)compõem a obra, efetivada no desenrolar do processo, ao passo de suas transformações inventivas.

Nesses rumos, também trafega a pesquisa cartográfica, ao demandar um mergulho do pesquisador num processo de aprendizado contínuo, pois "não dá para fazer cartografia rapidinho, passando questionário, ou fazendo uma entrevista rápida de 10 minutos no corredor, ou pegando um testemunho [...] é uma outra temporalidade da pesquisa e um outro tipo de disposição" (HETEROTOPIAS, 2012, 1'47”'), entrelaçados à própria vida do pesquisador, pois se trata de um aprendizado ininterrupto, sempre em andamento.

A cartografia concebe o ato de conhecer, como criador da realidade, e, para além dos eixos vertical (hierarquizante) e horizontal (homogeneizante), a cartografia aposta em um coletivo transversal, desestabilizador de fronteiras e representações. A divisão clara, que define rigorosamente quem é (e o que é) o pesquisador e o pesquisado, desestrutura-se por meio da ideia de coletivo. A transversalidade produz uma desestabilização de fronteiras préestabelecidas ao atravessar o eixo vertical, hierarquizador das diferenças, e, o horizontal, que iguala e homogeneíza, produzindo assim, uma dimensão coletiva da complexidade investigada, potencializando saberes até então excluídos (KASTRUP; PASSOS, 2014). Assim, um plano comum não é simplesmente um conjunto, uma somatória, ou uma reunião de objetos e atores em um espaço liso, homogêneo, operando relações identitárias, mas, noutros turnos, mescla singularidades heterogêneas, num plano pré-individual e coletivo, como uma confluência de vetores, ou, "um fundo virtual, apresentando-se como uma vitalidade social pré-individual, pura

\footnotetext{
${ }^{11}$ Vídeo com o processo do Caminhando, disponível em: 〈https://www.youtube.com/watch?v=3sP-uT5DQLM>. Acesso em: 30 mar. 2018.

${ }^{12}$ O Mundo de Lygia Clark - Biografia. Disponível em: 〈http://www.lygiaclark.org.br/biografiaPT.asp >. Acesso em: 30 mar. 2018.

${ }^{13}$ Dos trechos dos diários de Lygia Clark, disponíveis em: 〈http://www.lygiaclark.org.br/biografia/xml.asp〉. Acesso em: 30 mar. 2018.
} 
heterogeneidade não totalizável [...] funciona como foco de resistência em relação à captura pelas diferentes lógicas homogeneizantes e totalizantes" (KASTRUP; PASSOS, 2014, p.16).

Pensando com a ideia de partilha do sensível de Jacques Rancière, entendemos o comum como algo ao qual pertencemos e com o qual partilhamos. Um movimento transversal e político que destaca a importância dos modos de fazer comunitários, nos quais a partilha do sensível se efetiva por movimentos de coexistência em territórios e compartilhamentos de atividades e modos de fazer. (KASTRUP; PASSOS, 2014, p.20-22).

Nesse caminhar, a construção e o acesso a um plano comum pode produzir movimentos de transversalidade na pesquisa por três níveis de inclusão (KASTRUP; PASSOS, 2014):

1. Lateralização (os sujeitos e objetos lado a lado): o pesquisador sai da terceira pessoa em uma relação vertical. As experiências relacionais passam a ser colheitas e trocas e não apenas coletas de dados. $\mathrm{O}$ pesquisador constrói o manejo conforme o caminhar, e, as vivências entre pesquisar e cuidar da experiência constituem-se como dimensões inseparáveis da entrevista e do processo de entrevista;

2. Análise dos pressupostos da pesquisa: esse movimento de lateralização promove tensões e constantes movimentos de hódos-metá, demandando do pesquisador frequentes questionamentos dos pressupostos da pesquisa;

3. Movimentos coletivos: ao habitar o terceiro nível inclusivo, um movimento de experiência coletiva nas relações é efetivado, compondo uma abertura para diferentes percepções entre pesquisador e pesquisado(s), sendo necessária uma "ampliação do padrão comunicacional entre os grupos de interesse envolvidos" (KASTRUP; PASSOS, 2014, p.33).

O comum, habita nas experiências, nas conexões transversais em constante construção, afrouxa os limites, questiona as fronteiras, produz conexões comuns e heterogêneas. A produção desse território também se dá por meio da tradução, como encara François Jullien, como "uma zona de aventura" (KASTRUP e PASSOS, 2014, p. 34), um movimento de trânsito entre linguagens, porém sem uma língua referencial. Nesse caminhando, estamos "sempre numa língua ou noutra, não há uma língua por trás que constitua um solo seguro que garanta a passagem de uma a outra" (p. 34). Não se trata de analogias, ou encaixes de formas e representações pré-estabelecidas, mas sim de produção de equivalentes, como "sintonia no plano de forças" (p. 34), de compreensão e construção de cruzamentos possíveis entre duas línguas, imbricando, para além "do reconhecimento das formas [...] vetores transversais que lhe dão consistência, ou seja, atmosferas, ritmos, velocidades e intensidades que configuram a dinâmica das formas" (KASTRUP e PASSOS, 2014, p. 36).

Nesta senda, o texto A entrevista na pesquisa cartográfica: a experiência do dizer, de Tedesco, Sade e Caliman (2014), nos trouxe pistas para pensar a realização de nossas entrevistas, nas quais buscamos acompanhar os movimentos e as rupturas como imanentes ao processo da pesquisa. Uma entrevista como "A" experiência, não apenas como mediadora de experiências, mas como um momento vivido pelo entrevistador e pelo entrevistado, o qual pode ativar processos e transformações de forças coletivas. A tessitura do caminhando movimentase pois, num hódos-metá. Não se tratam de procedimentos inalteráveis, mas de um processo praticado, um manejo no qual escolhemos, apostamos, experimentamos e compartilhamos, entendendo a entrevista como um diálogo, "um passeio, que segue múltiplos vetores" (TEDESCO; SADE; CALIMAN, 2014, p. 113). 
Entre 2009 e 2016 dialogamos com diversos operadores cinematográficos, em especial aqueles com quem coabitamos na Cinemateca Brasileira. Adentrar seus grupos, compreendia tomar parte em acordos tácitos de partilhas de conhecimentos, bem como engajar-se em traduções e jogos, os quais percebíamos somente em ato, conforme vivíamos e experimentávamos o caminhando desses anos de convivência.

\section{Um jogo de dados educacional}

A radicalidade desse canto perigoso encontra no ato do pensamento sua materialidade. Isso nos convoca a um jogo educacional trançado pelo jogo de dados do pensar. Se este pode ser um lance de dados, tal como nos sugere o poeta Mallarmé, ele é risco, uma vez que, ao evocar o possível da multiplicidade e formatar contingências, se afirma e se atualiza o retorno do acaso do pensamento no próximo lance. Ora, educação é território de fatalidade de vida, jamais promessa de sobrevida metafísica. Requer amar a fatalidade do risco: jogar dados com o pensamento, fazê-lo cantar, ainda que. (RIBEIRO, 2009, p. 65).

Nas entrevistas com os operadores cinematográficos, percebemos diferenças nos modos de conduzirmos as conversações. Buscávamos compor com o ritmo de cada entrevistado, levando em conta a peculiaridade de termos encontrado poucas publicações sobre a profissão de operador cinematográfico (uma das primeiras faíscas dessa pesquisa), e que "a menor diretividade muitas vezes é utilizada para atingir um saber determinado, mas que estaria, até então, inacessível" (TEDESCO; SADE; CALIMAN, 2014, p. 109). O manejo das entrevistas com os projecionistas requereu pois, um cuidado diferente do lidar com os demais entrevistados. Claro, cada caso é um caso, cada entrevista nos proporciona conhecer territórios, ritmos e ideias singulares, mas, percebemos processualmente, a constituição de um plano comum nas entrevistas com os operadores.

Comumente, nos preocupávamos com o tempo de cada entrevista, por isso tínhamos um roteiro de perguntas, o qual seguíamos conforme a vivência da conversa solicitava. Atentávamos pois, às tensões entre entrevistador e entrevistado tendo em conta a lateralização produzida pelo movimento cartográfico.

A condução das entrevistas com os projecionistas se deu, na maioria das vezes, como processos permeados por espécies de 'jogos de vai-e-vem' e por testes. Em alguns momentos eles nos testavam ao longo da conversa, inquirindo se fazíamos mesmo parte daquele território, questionando se conhecíamos ou não determinado equipamento, ou se já tínhamos vivido determinada situação. A depender do vínculo estabelecido, os momentos em que desconhecíamos o assunto constituíam-se como oportunidades do entrevistado assumir uma postura diferente: o corpo mudava os trejeitos. Ele passava a ser ou um professor, ou um 'jogador-que-está-com-a-bola' Nesse momento do jogo, pausávamos o fluxo de perguntas-respostas e aguçávamos os ouvidos a aprender, ou, se fosse o caso, a 'perder-a-bola', a 'tomar-o-gol'. Noutros fluxos, percebemos também não bastar uma atitude inativa: por vezes precisávamos nos dispor a uma doação mais profunda, não se tratando de uma disputa, mas de momentos de troca, de construções coletivas. Mesmo nas entrevistas em que diálogos mais agressivos tomavam forma, buscávamos retomar o manejo do modo mais gradual possível. Não estávamos o tempo inteiro 'com-a-bola', se necessário, deixávamos a posição de entrevistadores.

Algumas percepções comuns de manejos de máquinas entre nós e os operadores ocorreram por nossas experiências com a área técnica de áudio. No período em que trabalhamos 
na Cinemateca Brasileira percebemos essas conexões, as quais culminaram em nossas partilhas de saberes. A cabine de projeção constituía-se como um espaço importante às relações de poder dos operadores. Percebemos que, naquele espaço, deveríamos demonstrar respeito a tal jurisdição. Desacatos naqueles territórios, especialmente em se tratando da cabine de projeção e das práticas do trabalho técnico, poderiam provocar efeitos catastroficamente destruidores dos vínculos: uma agressão à delicadeza da confiança estabelecida. Alexandro Genaro dizia que um operador cinematográfico só consegue exercer sua profissão sendo "senhor do seu local de trabalho ${ }^{14 ",}$, pois, pela exibição tratar-se de um espetáculo ao vivo, ele precisa necessariamente dominar cada meandro da cabine.

Essa ideia de jogo vincula-se às nossas partilhas de saberes, pois quando iniciamos a convivência na Cinemateca, em 2009, lhes assoberbavam os problemas técnicos relacionados ao áudio, principalmente aos ajustes técnicos necessários em palestras e eventos. Eles dominavam o manejo das sessões de filmes, mas trepidavam no controle dos microfones e das gravações de áudio.

Havia um problema técnico inerente àquelas salas de cinema, relativo ao posicionamento das caixas de som. Problema este que complicava a captação sonora de oradores, pois a ocorrência de microfonias era intrínseca àquele desenho do sistema de endereçamento sonoro, já que as caixas de som e os microfones dos palestrantes sempre se encontravam espacialmente, apontando um para o outro, e, retroalimentando-se ${ }^{15}$.

Propusemos algumas soluções emergenciais de redesenhos dos endereçamentos sonoros, as quais funcionaram por algum tempo. Havíamos produzido um movimento resolutivo para uma celeuma que os atormentava cotidianamente, pois, sempre que ocorriam tais problemas acústicos, seus superiores hierárquicos os taxavam de incompetentes, mas, aos operadores, escapava que essas supostas inabilidades eram inerentes ao posicionamento das caixas de som, o qual não fora desenhado para o uso de palestras, mas apenas para exibições de filmes. Nessa toada, além das constantes microfonias, tal ruído na comunicação se efetivava numa espécie de movimento viciado também de retroalimentação, pois eles não compreendiam quase nada de áudio que fugisse à operação do painel do sistema Dolby dos filmes em película ${ }^{16}$.

Dali adiante, éramos mais do que bem vindos à cabine, éramos agora requisitados! Isso não é trivial, tendo em vista que a cabine de projeção é um território predominantemente 'do projecionista', no qual ele exerce sua autoridade. Para se ter uma ideia, num contexto de projeções em película (daí uma hipótese acerca do estranhamento com a exibição digital, pois revira esse poderio), poderia acontecer de o operador não permitir o tráfego de outras pessoas na cabine. Se um projecionista enervasse com alguém (ouvimos algumas histórias sobre isso ao longo dos anos), ele poderia expulsar a pessoa da cabine, sob pena de não continuar a sessão

\footnotetext{
${ }^{14}$ Excerto obtido por meio de uma entrevista gravada em áudio no dia 05/09/2013, cujo entrevistado assinou termo de concessão.

${ }^{15}$ Inicialmente as salas de cinema da Cinemateca Brasileira foram pensadas para a realização de projeções de filmes. Utilizações mais amplas como, por exemplo, debates, palestras, ou mesmo simples apresentações das sessões com a utilização de microfones foram incorporadas processualmente nas práticas cotidianas de trabalho. Por esse motivo, a necessidade de um sistema de áudio auxiliar, apenas para os microfones, tornou-se imprescindível. O áudio dos filmes já é processado para utilizar as caixas de som de exibição. A utilização das mesmas caixas de som para os microfones ocasionalmente danificava os alto falantes, pois se um orador excedesse o volume de sua voz, e, se o técnico não conseguisse correr para a mesa de som e abaixar o nível sonoro enviado aos alto falantes, estes poderiam se romper. Existe um movimento comum na instituição, que busca preservar seus recursos, sejam eles filmes, equipamentos, mobiliários, etc. Por esses motivos desenhamos e instalamos um sistema de áudio auxiliar, que ainda segue sendo utilizado nas duas salas de cinema da sede da instituição em São Paulo-SP, Brasil.

${ }^{16}$ Operação que se resumia principalmente ao manejo de alguns botões já pré-configurados. Manejo este, bastante diferente do detalhamento das mesas de som às quais os recursos sonoros utilizados em palestras e eventos estavam conectados.
} 
caso sua ordem não fosse acatada. Ora, isso os fortalecia no contexto de uma sala de cinema com projeções em película: um espetáculo (principalmente num contexto 'ao vivo'), não pode parar, e os operadores cinematográficos sabem disso.

As requisições da cabine, para ajudarmos a resolver problemas técnico-operacionais de áudio nas mais diversas ocasiões, metamorfoseou nossa relação, ou melhor, coletivamente criamos uma relação via o comum 'áudio'. Daí, percebemos essa ideia de jogo, dos desafios acerca dos equipamentos de projeção que eles sempre nos propunham e que nós sempre perdíamos (e assim devia ser). Estabelecemos juntos um 'jogo-troca', agora com o áudio. Passamos a ensiná-los o que sabíamos de áudio. Para tal, sistematizamos alguns conhecimentos e práticas, e experimentamos juntos os desdobramentos disso. Sandro ${ }^{17}$ foi um grande parceiro nesse processo, assim como em tantos outros naquele contexto ${ }^{18}$. Trabalhamos juntos entre 2009 e 2013, período no qual ele foi promovido a chefe de cabine pela então diretoria da Cinemateca. Muito contente com a promoção (estávamos entre o final de 2009 e o início de 2010), dedicou-se de tal forma aos estudos de áudio que, alguns anos depois (por volta de 2012), regozijou-se ao nos dizer que, àquela altura, já sabia muito mais de áudio do que nós. Novamente nós 'perdíamos' o 'jogo', e, assim devia ser.

\section{Considerações finais}

As disputas e negociações entre os atores envolvidos na cadeia audiovisual brasileira no que diz respeito às escolhas tecnológicas de cada período histórico, efetivaram-se por meio de processos intrinsecamente relacionados aos suportes padrões vigentes. Os modos de fazer e pensar o cinema relacionados aos formatos digitais diferem substancialmente daqueles outrora praticados com as películas fílmicas. Assim, a maioria das distribuidoras cinematográficas não trabalha mais com filmes em película e uma outra forma de lidar com a exibição entra em cena, por meio da qual, facilidades e possibilidades de acesso e difusão ganham amplitude, ao mesmo tempo que produzem drásticas rupturas procedimentais, como por exemplo, as mudanças dos expedientes técnicos nas cabines de projeção, atreladas às demissões em massa de projecionistas, profissionais até então especializados na tecnologia padrão anterior - projetores mecânicos e películas.

Borde (1984) nos ensina quão catastróficas foram as três ondas de destruição para a história e para as práticas cinematográficas, pois muitos materiais se perderam em cada um dos períodos, tendo em vista a necessidade emergencial característica de cada um deles, de descartar rapidamente corpos fílmicos não mais desejados, liberando assim, espaço para os novos formatos demandados. Percebemos um elevado grau disruptivo com a inserção do cinema digital como corpo fílmico vigente, característica esta que faz de tal processo, uma quarta onda de destruição, a qual periga dragar ao descarte não apenas as películas, mas também as miríades de saberes, conhecimentos, equipamentos e também de recursos humanos (como os projecionistas), atreladas aos modos de fazer e pensar o cinema com películas como suporte padrão das exibições.

No soprar dos ventos dessas ondas de destruição, dezenas de operadores cinematográficos estão sendo demitidos, uma massa de desempregados agrupando uma significativa parcela de capacidade produtiva ociosa, profissionais que possuem saberes e conhecimentos importantes, os quais poderiam ser incorporados nesses novos modos da produção, distribuição e exibição digital, bem como aos processos de preservação e acesso. Noutros turnos, percebemos que

\footnotetext{
${ }^{17}$ Sandro é o nome adotado por Alexandro Genaro como projecionista, também é uma prática comum entre diversos operadores, adotar um outro nome como profissional, assunto no qual não nos deteremos neste momento. ${ }^{18}$ Mais em Gonçalves (2013; 2016)
} 
apesar de certa repulsa pela tecnologia que lhes ceifa os empregos, há uma paixão incontinente pelo manuseio de imagens digitais em smartphones, com os quais se comunicam em grupos de redes sociais, cravando de algum modo, movimentos de resistência frente ao horizonte trágico de esboroamento de referenciais, partilhas e da fragmentação do próprio corpo - se considerarmos a força dos agenciamentos estabelecidos anos a fio com a maquinaria da projeção analógica.

Outrossim, assistimos à efervescência diante das possibilidades que as tecnologias digitais oferecem. Essa pesquisa e as entrevistas que realizamos, por exemplo, não poderiam comemorar esse feito, de deslizar entre diversos suportes, não fossem as possibilidades de baixo custo (câmera de vídeo portátil, gravador de áudio, câmera fotográfica, scanner, websites, Skype, e-mail, redes sociais, etc.) possibilitadas pelos formatos digitais. Os corpos-pixel possibilitam, pois, múltiplas entradas, modos de fazer os quais compõem com as oscilações das ondas de destruição, a imanência dos balés de catástrofe da história do cinema e de nossas próprias vidas, tendo em vista habitarmos os territórios afetados pelos efeitos dessa quarta onda de destruição.

Nesse caminhando, a questão sobre o que seria o cinema metamorfoseia seu traços, pois buscamos continuamente desestabilizar o verbo "ser". Ao invés de pensar o que "é" o cinema ou o audiovisual, tentamos experimentar outros modos de habitar tais territórios. Afinal, procedimentos operacionais que demandam de um profissional o manejo de materiais em uma tela e não mais em projetores mecânicos, podem ou não tratar-se de uma projeção cinematográfica. O cinema pode ser invenção, mercado, indústria, sonho, vida, documento, sortimento, requerimento, fomento, cruzamento, alento... tudo ao mesmo tempo agora.

As partilhas de saberes experienciadas com os operadores cinematográficos tomaram parte em nossas próprias vidas, de modo que, pensar com tal processo, chamando-o de cartográfico, transversal, jogo de dados, etc., tratou-se de uma tentativa de, na escrita, produzir um território com as contingências que vivemos ao apostar num modo de pesquisar ad hoc. Nesses fluxos, não há metodologias a priori: estamos, pois, imersos à tragicidade desse balé de catástrofe, dessa da onda de destruição que habitamos. Assim dançam esses corpos fílmicos contemporâneos, num caminhando costurado com lusco-fuscos, sombras e clarões. E, nesses fluxos, jogamos dados com o pensamento, arriscamos os lances, e, ecoamos nosso canto, ainda que.

\section{Referências}

ACADEMIA DE ARTES E CIÊNCIAS CINEMATOGRÁFICAS [AMPAS]. O dilema digital: questões estratégicas na guarda e no acesso a materiais cinematográficos digitais. AMPAS: Estados Unidos, 2007. Tradução produzida pela Cinemateca Brasileira a partir da $2^{a}$ impressão digital, de fevereiro de 2008, com autorização da Academia de Artes e Ciências Cinematográficas (AMPAS), São Paulo: Cinemateca Brasileira, 2009.

ACADEMIA DE ARTES E CIÊNCIAS CINEMATOGRÁFICAS [AMPAS]. $O$ dilema digital 2: perspectivas de cineastas independentes, documentaristas e arquivos audiovisuais sem fins lucrativos. AMPAS: Estados Unidos, 2012. Traduzido por Millard Schisler; Osvaldo Emery e Patricia de Filippi. São Paulo: Instituto Butantan, 2015.

AQUINO, Julio Groppa. Diálogos em delay: especulações em torno de uma temporalidade outra do encontro pedagógico. Educ. Pesqui., São Paulo, Ahead of print, ago. 2016.

AUGER, François. Projecionista de uma cinemateca (O caso da Cinemateca de Quebec). Journal of Film Preservation, FIAF, n. 67, 2004. In: PRESERVAÇAO AUDIOVISUAL. Blog. Traduzido 
por Fausto Douglas Correa Júnior, com revisão de Rafael de Luna. Disponível em: $<$ http://preservacaoaudiovisual.blogspot.com.br/2009/03/projecionista-de-uma-cinemateca.html $>$. Acesso em: 24 set. 2013.

BORDE, Raymond. Avatares de un arte vulnerable. El Correo de la Unesco. Año XXXVII, n. 8. p. 4-6. Paris: Unesco, 1984.

COELHO, Fernanda. Manual de manuseio de películas cinematográficas: procedimentos utilizados na Cinemateca Brasileira. 3. ed. São Paulo: Imprensa Oficial do Estado: Cinemateca Brasileira. 2006.

COMOLLI, Jean-Louis. Ver e poder: a inocência perdida. Cinema, televisão, ficção, documentário. Belo Horizonte: Editora da UFMG. 2008.

COSTA, Silvia Ramos Gomes da. As ondas de destruição: a efemeridade do artefato tecnológico e o desafio da preservação audiovisual. Orientadora: Leila Beatriz Ribeiro. Dissertação (Mestrado em Memória Social) - Universidade Federal do Estado do Rio de Janeiro, Rio de Janeiro, 120 f. 2013.

DELEUZE, Gilles. Nietzsche e a Filosofia. 1. ed. Brasileira. Tradução de Ruth Joffily Dias e Edmundo Fernandes Dias. Rio de Janeiro: Editora Rio, 1976.

GONÇALVES, Ingrid Rodrigues. Artesãos da imagem: os projecionistas e suas geografias. In: III Colóquio Internacional "A educação pelas imagens e suas geografias". Anais... Vitória, Espírito Santo, 2013.

GONÇALVES, Ingrid Rodrigues. Uma dança dos corpos fílmicos. ETD - Educação Temática Digital, Campinas, SP, v. 18, n. 4, p. 835-856, nov. 2016. ISSN 1676-2592. Disponível em: <http://periodicos.sbu.unicamp.br/ojs/index.php/etd/article/view/8646440>. Acesso em: 16 nov. 2016. doi: 〈http://dx.doi.org/10.20396/etd.v18i4.8646440>.

KASTRUP, Virgínia. O funcionamento da atenção no trabalho do cartógrafo. In: PASSOS, Eduardo; KASTRUP, Virginia; ESCÓSSIA, Liliana da (Org.). Pistas do método da cartografia: Pesquisa intervenção e produção de subjetividade. Porto Alegre: Sulina. 2009.

KASTRUP, Virgínia; PASSOS, Eduardo Henrique. Cartografar é traçar um plano comum. In: PASSOS, Eduardo; KASTRUP, Virginia; TEDESCO, Silvia (Org.). Pistas do método da cartografia: a experiência da pesquisa e o plano comum. Porto Alegre: Sulina. v. 2. 2014.

MARSON, Melina Izar. Cinema e Políticas de Estado: da Embrafilme à Ancine. São Paulo: Escrituras Editora. V. I. 2012.

MIRANDA, André. Processo de modernização dos cinemas brasileiros está atrasado. O Globo, Rio de Janeiro, RJ. 06 jan. 2014. Cultura. Disponível em: 〈http://oglobo.globo.com/cultura/processode-modernizacao-dos-cinemas-brasileiros-esta-atrasado-11216067>. Acesso em: 07 out. 2015.

OCA/ ANCINE. Observatório Brasileiro do Cinema e do Audiovisual/ Agência Nacional do Cinema. Informe Anual 2016 - 01 de janeiro a 31 de dezembro. Segmento de Salas de Exibição: Informe de Mercado. Disponível em: <https://oca.ancine.gov.br/informe-anual-exibi\%C3\%A7\%C3\%A3o2016-0>. Acesso em: 02 set. 2017. 
PASSOS, Eduardo Henrique; BARROS, Regina Benevides de. A cartografia como método de pesquisa-intervenção. In: PASSOS, Eduardo; KASTRUP, Virginia; ESCÓSSIA, Liliana da (Org.). Pistas do Método da Cartografia: pesquisa-intervenção e produção de subjetividade. Porto Alegre: Sulina. 2009. 207 p.

RIBEIRO, Cintya Regina. Jogo de dados. In: AQUINO, Julio Groppa; CORAZZA, Sandra Mara. (Org.). Abecedário: educação da diferença. 1. ed. Campinas - SP: Papirus, 2009. p. 102105.

ROLNIK, Suely. Cartografia Sentimental: transformações contemporâneas do desejo. 2. ed. Porto Alegre: Sulina; Editora da UFRGS, 247 p. 2014.

ROSENFELD, Anatol. Cinema: Arte \& Indústria. São Paulo: Editora Perspectiva. 2002.

TEDESCO, Silvia Helena; SADE, Christian; CALIMAN, Luciana Vieira. Pista da Entrevista. A entrevista na pesquisa cartográfica: a experiência do dizer. In: PASSOS, Eduardo; KASTRUP, Virgínia; TEDESCO, Silvia. (Org.) Pistas do método da cartografia: a experiência da pesquisa e o plano comum. 310 p. v. 2. p. 66-91. Porto Alegre: Sulina, 2014.

\section{Vídeos}

HETEROTOPIAS - encontro 01/maio - parte II. Publicado no canal do Vimeo Habitação Alpendre. 11 jul. 2012. Disponível em: 〈https://vimeo.com/45587687〉. Acesso em: 20 ago. 2015.

PASSOS, Eduardo. Clínica Comum e as áreas profissionais. Palestra ministrada pelo Prof. Dr. Eduardo Passos. Publicado no Youtube em 17 fev. 2014. Disponível em: <https://www.youtube.com/watch?v=9SUJysExsAQ>. Acesso em: 12 nov. 2015.

\section{Agradecimentos}

Agradecemos às inenarráveis contribuições de Alexandro Nascimento Genaro, Carmen Lucia Genaro e Maria Fernanda Curado Coelho. 